OPEN ACCESS

Edited by:

Lígia M. Saraiva,

Universidade Nova de Lisboa,

Portugal

Reviewed by:

Moritz Treeck,

Francis Crick Institute,

United Kingdom

Chong Zhang,

Tsinghua University, China

*Correspondence:

Quan Wang

wangquan@shvri.ac.cn

Wei Jiang

jiangweijw99@163.com

Specialty section:

This article was submitted to

Infectious Diseases,

a section of the journal

Frontiers in Microbiology

Received: 22 February 2021

Accepted: 03 May 2021

Published: 07 June 2021

Citation:

Chen Y, Liu Q, Xue J-X,

Zhang $M-Y$, Geng $X-L$, Wang $Q$ and

Jiang W (2021) Genome-Wide

CRISPR/Cas9 Screen Identifies New

Genes Critical for Defense Against

Oxidant Stress in Toxoplasma gondii.

Front. Microbiol. 12:670705.

doi: 10.3389/fmicb.2021.670705

\section{Genome-Wide CRISPR/Cas9 Screen Identifies New Genes Critical for Defense Against Oxidant Stress in Toxoplasma gondii}

\author{
Yun Chen ${ }^{1}$, Qi Liu' ${ }^{1}$, Jun-Xin Xue ${ }^{2}$, Man-Yu Zhang ${ }^{1}$, Xiao-Ling Geng ${ }^{1}$, Quan Wang ${ }^{1 *}$ and \\ Wei Jiang ${ }^{1 *}$ \\ 'Shanghai Veterinary Research Institute, Chinese Academy of Agricultural Sciences, Shanghai, China, ${ }^{2}$ Shanghai Customs \\ District P. R. C. China, Shanghai, China
}

Toxoplasma gondii is one of the most widespread apicomplexans and can cause serious infections in humans and animals. Its antioxidant system plays an important role in defending against oxidant stress imposed by the host. Some genes encoding the antioxidant enzymes of $T$. gondii have been identified; however, critical genes that function in response to reactive oxygen species (ROS) stress are still poorly understood. Here, we performed genome-wide CRISPR/Cas9 loss-of-function screening in the T. gondii $\mathrm{RH}$ strain to identify potential genes contributing to the ROS stress response. Under hydrogen peroxide treatment, 30 single guide RNAs targeting high-confidence genes were identified, including some known important antioxidant genes such as catalase and peroxiredoxin PRX3. In addition, several previously uncharacterized genes were identified, among which five hypothetical protein-coding genes, namely, HP1-HP5, were selected for further functional characterization. Targeted deletion of HP1 in T. gondii $\mathrm{RH}$ led to significant sensitivity to $\mathrm{H}_{2} \mathrm{O}_{2}$, suggesting that $\mathrm{HP} 1$ is critical for oxidative stress management. Furthermore, loss of HP1 led to decreased antioxidant capacity, invasion efficiency, and proliferation in vitro. In vivo results also revealed that the survival time of mice infected with the HP1-KO strain was significantly prolonged relative to that of mice infected with the wild-type strain. Altogether, these findings demonstrate that the CRISPR/Cas9 system can be used to identify potential genes critical for oxidative stress management. Furthermore, HP1 may confer protection against oxidative damage and contributes to $T$. gondii virulence in mice.

Keywords: Toxoplasma gondii, antioxidant, oxidative stress, gene knockout, virulence

\section{INTRODUCTION}

Toxoplasma gondii is one of the most successful intracellular apicomplexan parasites because it can infect almost any type of nucleated cell in warm-blooded animals (Webster, 2010). Most T. gondii infections are asymptomatic or mild symptoms, but infections in immunocompromised patients can cause severe disease manifestations. Infections in pregnancy can cause miscarriage, fetus death, nervous system problems of the newborn. Livestock infection with T. gondii can cause 
considerable economic losses (Blader and Saeij, 2009; Silva and Langoni, 2009). Toxoplasma is successful as a widespread pathogen because multiple hosts become infected through ingestion of water or vegetable contaminated with oocysts or undercooked meat containing viable tissue cysts.

Toxoplasma infection is a complex process consisting of multiple, independently regulated steps. Within its hosts, T. gondii have remarkable ability to avoid immune surveillance and establish infection (Hunter and Sibley, 2012). Many virulence factors of $T$. gondii involved in the regulation of host immune responses and signal transduction have been studied, including the rhoptry proteins (ROP) 5 and 18, which are important for protecting T. gondii from clearance by phosphorylating immunerelated GTPases in the host (Behnke et al., 2012; Hermanns et al., 2016). TgIST and ROP16 can translocate to the nucleus or cytoplasm and manipulate host gene expression by inhibiting related transcription factors (Ong et al., 2010; Gay et al., 2016). In addition, pathogen infection induced ROS production in macrophages and neutrophils, triggering an oxidative burst (Murray et al., 1985). Upregulation of ROS has serious deleterious effects, including oxidative DNA damage and lipid peroxidation (Packialakshmi and Zhou, 2018); thus, it is toxic to and can inhibit the intracellular proliferation of T. gondii (Lajarin et al., 1999; Aline et al., 2002; Xu et al., 2011; MacMicking, 2012). For successful infection in the host cell, T. gondii must overcome the reactive oxygen species (ROS) secreted by immune cells (Lajarin et al., 1999; West et al., 2011; Yang et al., 2020). As such, an effective and networked antioxidant system is essential for protecting $T$. gondii from oxygen toxicity and damage, scavenging ROS, and maintaining intracellular redox homeostasis (Kapoor and Banyal, 2009).

To date, the antioxidant enzymes superoxide dismutase (SOD), catalase (CAT), and peroxiredoxins (Prx) have been identified in T. gondii (Dincel and Atmaca, 2016). The main function of SOD is to catalyze the conversion of excess superoxide anions $\left(\mathrm{O}_{2}{ }^{-}\right)$into hydrogen peroxide and oxygen (Fukai and Ushio-Fukai, 2011). CAT is a potent $\mathrm{H}_{2} \mathrm{O}_{2}$-detoxifying enzyme that acts downstream of SOD, which can convert $\mathrm{H}_{2} \mathrm{O}_{2}$ into molecules of water and oxygen, thereby helping T. gondii evade the macrophage respiratory burst (Ding et al., 2004). In addition, glutathione peroxidases and the Prxs family contribute to the decomposition of $\mathrm{H}_{2} \mathrm{O}_{2}$ (Kaasch and Joiner, 2015). Furthermore, our previous study showed that thioredoxin reductase (TR) is an important antioxidant enzyme and a necessary virulence factor of T. gondii with an important role in the resistance to oxidative damage by maintaining thioredoxin (Trx)-reduction state (Kim et al., 2017; Xue et al., 2017). In addition, T. gondii uses the thiolreduction system, including glutathione, Trx, glutaredoxin, and specific reductases, to resist oxidative damage. These enzymes, which are associated with the antioxidant system, play essential roles during parasite survival and infection (Padín-Irizarry et al., 2016). However, it remains unclear whether other unidentified genes are involved in the resistance to host ROS (Boczoń, 2002).

Genome-wide CRISPR/Cas9 screen are powerful tools for identifying essential genes under a specific condition and studying the molecular mechanisms associated with specific phenotypes. Currently, screening with genome-wide
CRISPR/Cas9 gene-editing technology has been successfully applied to human cells and microorganisms (Shalem et al., 2014; Han et al., 2018) and has been used to identify previously uncharacterized functional gene in T. gondii (Sidik et al., 2016, 2018). For example, the dense granule protein GRA45 is a virulence factor identified using genome-wide screening (Wang et al., 2020). Therefore, genome-wide CRISPR/Cas9 screen can aid in the identification of new antioxidant genes and further reveal the ROS-scavenging mechanisms of T. gondii.

In this study, genome-wide CRISPR/Cas9 technology was used to identify new antioxidant-related genes in T. gondii under $\mathrm{H}_{2} \mathrm{O}_{2}$-induced oxidative stress, and high-throughput sequencing was used to screen which mutants were lost by the screen. Several genes with significant deletion of single-guide RNAs (sgRNAs) were identified, among which five hypothetical protein (HP)coding genes were further analyzed. Functional characterization of parasites lacking these five hypothetical genes was performed by assessing their invasion potential, intracellular replication, $\mathrm{H}_{2} \mathrm{O}_{2}$ resistance, ROS levels, and total antioxidant capacity (TAOC) in vitro, as well as their infection potential in vivo.

\section{MATERIALS AND METHODS}

\section{Cell Culture and T. gondii Maintenance}

Toxoplasma gondii RH parasites and cells were stored in our laboratory. African green monkey kidney (Vero) cells and murine macrophage (Raw264.7) cells were maintained in Dulbecco's modified Eagle medium (DMEM) supplemented with $10 \%$ heatinactivated fetal bovine serum (FBS), 2 mM glutamine, $100 \mathrm{kU} / \mathrm{L}$ streptomycin, and $400 \mathrm{kU} / \mathrm{L}$ penicillin (Beijing Solarbio Science \& Technology Co., Beijing, China). A TR knockout strain (TRKO) was constructed by Xue et al. (2017), and a pseudokinase ROP5 knockout strain ( $R O P 5-\mathrm{KO})$ was constructed as previously described by Xue et al. (2017). All T. gondii strains used in this study were passaged on Vero cells maintained at $37^{\circ} \mathrm{C}$ in a $5 \%$ $\mathrm{CO}_{2}$ incubator.

\section{Animals}

Eight-weeks-old female Kunming mice were purchased from the Shanghai Jiesijie Experimental Animal Company (Shanghai, China). All animal experimental procedures were performed in strict accordance with the approved guidelines of the Institutional Animal Care and Use Committee of the Shanghai Veterinary Research Institute.

\section{Plasmids}

The CRISPR Knockout Pooled Library (\#80636) and plasmids pCas9/chloramphenicol acetyltransferase (\#80323) and pCas9/decoy (\#80324) were acquired from Addgene (Watertown, MA, United States).

\section{Experimental Model of $\mathrm{H}_{2} \mathrm{O}_{2}$-Mediated Oxidative Stress}

To determine the maximum concentration of $\mathrm{H}_{2} \mathrm{O}_{2}$ that did not affect cell viability, Vero cells were seeded into 96-well plates 
$\left(2 \times 10^{5}\right.$ cells $\left./ \mathrm{mL}\right)$ and treated with different concentrations of $\mathrm{H}_{2} \mathrm{O}_{2}(0,100,200,300,400,500,600$, and $800 \mu \mathrm{M})$ (SigmaAldrich, St. Louis, MO, United States) for 6, 12, 24, and $48 \mathrm{~h}$. Subsequently, cell viability was assessed using a Cell Counting Kit-8 (CCK-8; Vazyme Biotech, Nanjing, China), in accordance with the manufacturer's instructions. Absorbance of the wells was measured with a microplate reader at $450 \mathrm{~nm}$. Four replicates were set up for each treatment and the percentage of live cells was expressed in comparison to untreated control cells.

Intracellular ROS levels were determined using the Reactive Oxygen Species Detection Assay Kit (Beyotime, Shanghai, China). Briefly, Vero cells were cultured in 6 -well plates $\left(1 \times 10^{6}\right.$ cells/well) and cultured for $24 \mathrm{~h}$. The medium was removed and replaced with fresh medium containing different concentrations (100 and $200 \mu \mathrm{M}$ ) of $\mathrm{H}_{2} \mathrm{O}_{2}$. After the treatment for 1, 2, 4, 6, 12 , or $24 \mathrm{~h}$, Vero cells were harvested, resuspended in serum-free medium, and incubated with $2^{\prime}, 7^{\prime}$-dichlorofluorescin diacetate (DCFH-DA, $10 \mu \mathrm{M}$ ) for $37^{\circ} \mathrm{C} 30 \mathrm{~min}$. Next, the cells were washed three times with serum-free DMEM to remove excess probe, and the fluorescence intensity was determined at excitation and emission wavelengths of 488 and $525 \mathrm{~nm}$, respectively, in a Synergy 2 fluorescence microplate reader (BioTek Instruments, Winooski, VT, United States).

To establish the timing at which to assess the differences between different strains in their sensitivity to $\mathrm{H}_{2} \mathrm{O}_{2}$, three strains were used. Among them, the TR-KO strain was used as a positive control, as it was previously reported to show high sensitivity to $\mathrm{H}_{2} \mathrm{O}_{2}$ treatment (Xue et al., 2017). The $\mathrm{RH}$ and ROP5-KO strains ( $R O P 5$ is not an antioxidant gene) were used as negative controls. Three extracellular parasite strains $\left(5 \times 10^{5}\right.$ tachyzoites per experimental group) were collected, suspended in serum-free DMEM containing $200 \mu \mathrm{M} \mathrm{H}_{2} \mathrm{O}_{2}$ for $15,30,45$, and $60 \mathrm{~min}$ at $37^{\circ} \mathrm{C}$. After incubation, the $\mathrm{H}_{2} \mathrm{O}_{2}$ was removed by centrifugation and treated tachyzoites were allowed to infect Vero cells in 12well plates. The survival of each strain was assessed by counting the number of vacuoles containing more than two parasites after $36 \mathrm{~h}$ of culture.

The inhibitory effect of $\mathrm{H}_{2} \mathrm{O}_{2}$ on the intracellular parasites was further assessed by counting the number of parasites in the vacuoles. Briefly, Vero cell grown in 12-well plates were infected with $5 \times 10^{5}$ tachyzoites of three strains, and cultured for $12 \mathrm{~h}$. Next, the Vero cells were washed, and complete medium (DMEM + 2\% FBS) with $200 \mu \mathrm{M} \mathrm{H}_{2} \mathrm{O}_{2}$ was added to each well in the treatment groups, for continuous culture. The number of parasites in the vacuoles was counted at $36 \mathrm{~h}$ post-invasion. Three independent experiments were conducted in triplicate, and at least 100 cells were counted.

\section{Genome-Wide CRISPR/Cas9-Mediated Screening}

Toxoplasma gondii genome-wide CRISPR/Cas9-mediated screening was performed as described by Sidik et al. (2018). Briefly, a Cas9-expressing strain (RH/Cas9) was constructed by co-transfecting the $\mathrm{RH}$ strain with the pCas9/chloramphenicol acetyltransferase and pCas9/decoy plasmids. Next, $500 \mu \mathrm{g}$ of a sgRNA library linearized with the AseI enzyme was transfected into approximately $8 \times 10^{8} \mathrm{RH} / \mathrm{Cas} 9$ parasites, which were separated into 16 individual 4-mm-gap electroporation cuvettes. Transfected parasites were allowed to infect 16 plates $\left(15 \mathrm{~cm}^{2}\right)$ of $80 \%$ confluent Vero cells. The medium was removed from each dish $24 \mathrm{~h}$ post-infection and replaced with a selective medium containing $3 \mu \mathrm{M}$ pyrimethamine and $10 \mu \mathrm{g} / \mathrm{mL}$ DNaseI (Sigma-Aldrich). Following natural egress, parasites were passaged in Vero cells and selected by pyrimethamine for two more generations. All mutants were equally assigned into a test group and a control group. The test group was incubated in DMEM containing $200 \mu \mathrm{M} \mathrm{H} \mathrm{H}_{2} \mathrm{O}_{2}$ at $37^{\circ} \mathrm{C}$ for $30 \mathrm{~min}$, and then the parasites were added to eight $15-\mathrm{cm}^{2}$ dishes of confluent Vero cells. After culturing for $12 \mathrm{~h}$, the medium was replaced with a fresh medium containing 200 $\mu \mathrm{M} \mathrm{H}_{2} \mathrm{O}_{2}$. The parasites were harvested at $48 \mathrm{~h}$ after infection (the time at which the mutant parasites nearly egressed from the host cells) and counted. At least $30 \%$ of the population was subjected to the same stimulation until the third passage. The experimental procedures and culture conditions of the control group were the same as those of the test group, except that $\mathrm{H}_{2} \mathrm{O}_{2}$ was not used. Parasites from the control group (TOX1) and test group (TOX2) were then harvested and used for genomic DNA extraction (Tiangen Biotech, Beijing, China) and polymerase chain reaction (PCR) amplification of the sgRNA with a barcoding primer (Supplementary Table 1), respectively. The samples were sent to Novogene Technology (Beijing, China) for sequencing on a HiSeq 2500 system (Illumina, San Diego, CA, United States).

The screening data were analyzed as previously described by Sidik et al. (2016). Briefly, sequencing reads were aligned to the sgRNA library sequences (Addgene), and the abundance of each sgRNA was calculated as raw read numbers. The $\log _{2}$-fold change between $\mathrm{H}_{2} \mathrm{O}_{2}$ treated and untreated samples was calculated for each sgRNA. Then, the screening score was calculated as the average $\log _{2}$-fold change of the top five most abundant sgRNA for each gene in the untreated sample, which ensured the minimal impact of random loss. In addition, the percentage change of sgRNA loss after $\mathrm{H}_{2} \mathrm{O}_{2}$ treatment was further calculated. Thirty sgRNAs with high loss percentages and loss numbers greater than 100 were selected. The final candidate genes were selected from the 30 sgRNA-targeted genes based on a low screening score and low phenotypic score.

\section{Construction of CAT-KO and HP-KO Parasites}

Knockout strains were constructed as described by Sidik et al. (2016). Briefly, specific sgRNAs targeting CAT and HPs were used to replace the sgRNA site in the pU6-DHFR plasmid via a ClonExpress MultiS one-step cloning kit (Vazyme Biotech). RH/Cas9 parasites $\left(1 \times 10^{7}\right)$ were transfected with $20 \mu \mathrm{g}$ of pU6-sgRNA-DHFR containing guides against different $H P$ or $C A T$, respectively. The stable mutants were selected with $3 \mathrm{mM}$ pyrimethamine at $24 \mathrm{~h}$ post-transfection, and single clones were obtained by limiting dilution. Positive single clones were identified by amplifying the target gene fragments by PCR. All primers used are listed in Supplementary Table 1. 


\section{Viability Assessment of Extracellular Parasites by $\mathrm{H}_{2} \mathrm{O}_{2}$ Sensitivity Assay}

To analyze the effect of $\mathrm{H}_{2} \mathrm{O}_{2}$ on the growth of the $\mathrm{RH}$ strain and constructed mutants, freshly egressed parasites were collected, passed through $5-\mu \mathrm{m}$ filters, washed once with serum-free DMEM, and treated with various concentrations of $\mathrm{H}_{2} \mathrm{O}_{2}$ for $30 \mathrm{~min}$ at $37^{\circ} \mathrm{C}$ and $5 \% \mathrm{CO}_{2}$. Treated and untreated parasites were allowed to invade Vero cells and cultured for $36 \mathrm{~h}$. Parasite viability was determined by counting the number of vacuoles containing more than two parasites under the microscope.

The effect of $\mathrm{H}_{2} \mathrm{O}_{2}$ on the replication of intracellular parasites was also evaluated. Briefly, purified parasites were allowed to infect Vero cells; after $12 \mathrm{~h}$ of continuous culture, non-invaded parasites were removed by washing the cells with phosphatebuffered saline (PBS) and placed in a fresh medium containing $200 \mu \mathrm{M} \mathrm{H}_{2} \mathrm{O}_{2}$. The parasites were continuously cultured in Vero cells for an additional $24 \mathrm{~h}$. The effect of $\mathrm{H}_{2} \mathrm{O}_{2}$ on the replication rate of the parasites was determined by counting the number of parasites per vacuole under the microscope and then averaging the number of parasites per vacuole.

\section{Detection of ROS, MDA, and T-AOC}

To validate the effect of candidate gene deletion on the antioxidant capacity of $T$. gondii, the ROS, malondialdehyde (MDA), and total antioxidant capacity (T-AOC) levels in each strain were evaluated. Purified tachyzoites $\left(1 \times 10^{7}\right)$ were incubated with DCFH-DA (Beyotime) at $37^{\circ} \mathrm{C}$ for $30 \mathrm{~min}$. These tachyzoites were washed three times with serum-free DMEM, and the total fluorescence intensity was measured with a Synergy 2 fluorescence microplate reader (BioTek Instruments). The level of total ROS in the mutants was calculated as a percentage of that observed for the RH strain. To investigate whether different strains affected the ROS levels secreted by macrophages, T. gondii-infected RAW264.7 murine macrophage cells were evaluated. Briefly, RAW264.7 cells were infected with tachyzoites at a ratio of 2:1, and the ROS levels of RAW264.7 cells were detected using DCFH-DA for 3, 6, 12, and $24 \mathrm{~h}$. The percentage compared to ROS levels in control (non-infected) RAW264.6 cells was calculated.

The MDA level in purified tachyzoites was determined using an MDA assay kit (Beyotime), and the absorbance of the lysate was measured at $532 \mathrm{~nm}$. The results are presented as MDA nanomolar per protein milligram. A TAOC assay kit (Beyotime) was used to determine T-AOC levels in the tachyzoites based on the ferric reducing ability of plasma. All assay procedures and calculation methods were performed in accordance with the manufacturer's instructions. The experiments were repeated three times.

\section{Plaque Assays}

Vero cells were infected with 500 freshly harvested parasites in a 6-well plate and grown in DMEM containing 2\% FBS with or without $200 \mu \mathrm{M} \mathrm{H}_{2} \mathrm{O}_{2}$. Each strain was assessed in triplicates. The $\mathrm{H}_{2} \mathrm{O}_{2}$-containing medium was removed and replaced with a normal medium $48 \mathrm{~h}$ after infection to avoid damaging the cells. Seven days post-transfection, the monolayers were rinsed with
PBS, fixed with $4 \%$ formaldehyde for 20 min, stained with crystal violet (Beyotime) for $10 \mathrm{~min}$, and washed with water. Plaque formation and plaque numbers were assessed under an Electron microscope (Nikon, Tokyo, Japan).

\section{Invasion and Proliferation Assays}

Carboxyfluorescein diacetate succinimidyl ester (CFDA-SE; Beyotime) was used to evaluate the invasion rates of the constructed knockout strains. The RH and mutant strains were labeled with CFDA-SE at $37^{\circ} \mathrm{C}$ for $20 \mathrm{~min}$ and then washed with PBS three times. Labeled parasites $\left(1 \times 10^{6}\right.$ per well $)$ were added to 6-well culture plates containing $90 \%$ confluent Vero cells and incubated at $37^{\circ} \mathrm{C}$ for $2 \mathrm{~h}$. Non-invasive parasites were rinsed with PBS. After $12 \mathrm{~h}$ of culture, the cell monolayer was detached with trypsin-EDTA (0.25\%), resuspended in DMEM supplemented with $10 \%$ FBS, and analyzed with a Cytomics FC 500 flow cytometer (Beckman Coulter, Brea, CA, United States).

To investigate the replication ability of the parasites, $\mathrm{RH}$ and constructed knockout parasites were used to infect Vero cells in a 6-well plate $\left(1 \times 10^{6}\right.$ parasites/well $)$ and incubated under normal growth conditions. Extracellular parasites were rinsed with PBS $12 \mathrm{~h}$ post-infection and cultured for more than $24 \mathrm{~h}$. The number of parasites per vacuole was counted under the microscope for 100 vacuoles. Three independent experiments were conducted in triplicates.

\section{Virulence Testing}

Kunming female mice ( 8 weeks old, $n=10$ ) were intraperitoneally injected with purified parasites of the RH or the constructed knockout strains $\left(1 \times 10^{3}\right.$ parasites $)$ or with the same volume of sterile PBS (negative control). The survival of mice upon infection was monitored to evaluate the virulence of the parasites. Cumulative mortality was plotted and analyzed using GraphPad Prism 5 software (GraphPad Software, San Diego, CA, United States).

\section{Statistical Analysis}

Statistical analysis was performed using SPSS version 20 software (SPSS, Inc., Chicago, IL, United States). Significance was determined by one-way analysis of variance, and all results are presented as the means \pm standard deviation. $P<0.05$ was considered to indicate statistically significant differences.

\section{RESULTS}

\section{Optimization of Oxidative Stress Experimental Model}

In previous studies, $\mathrm{H}_{2} \mathrm{O}_{2}$ treatment of extracellular T. gondii with antioxidant gene deletion resulted in a remarkable decrease in T. gondii viability (Xue et al., 2017). Because T. gondii is an obligate intracellular parasite, in addition to treatment with extracellular parasites, we established an oxidative stress model of Vero cells to screen for antioxidant-related genes in T. gondii. First, Vero cells were treated with different concentrations of $\mathrm{H}_{2} \mathrm{O}_{2}$, and cell viability was evaluated using the CCK8 assay. The results demonstrated that $\mathrm{H}_{2} \mathrm{O}_{2}$ inhibited cell 
A
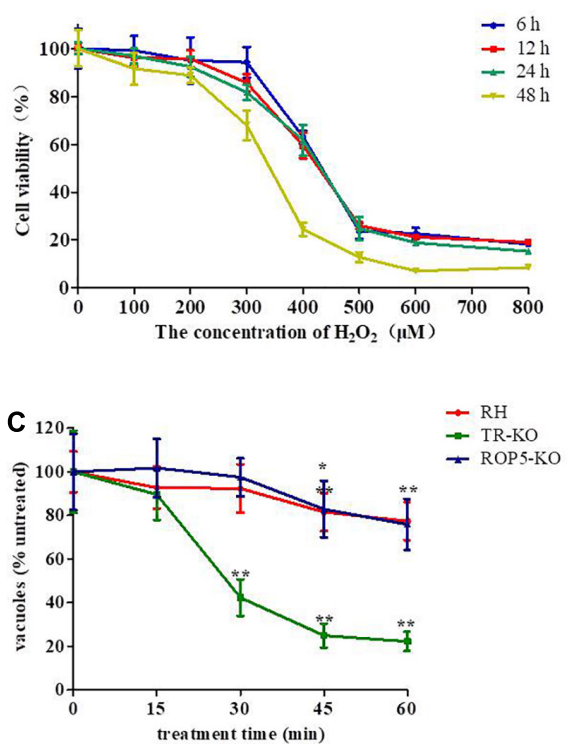

B

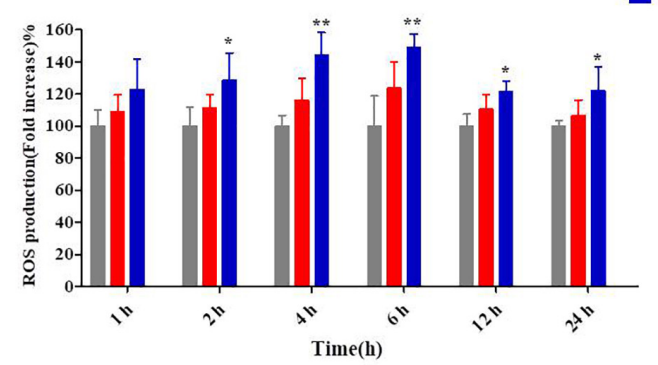

D

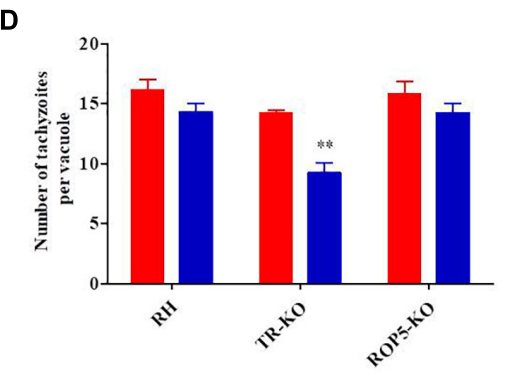

FIGURE 1 | Effect of $\mathrm{H}_{2} \mathrm{O}_{2}$ on Vero cells and different strains of Toxoplasma gondii. (A) Vero cells were treated with various concentrations of $\mathrm{H}_{2} \mathrm{O}_{2}(0,100,200$, $300,400,500,600$, and $800 \mu \mathrm{M}$ ) for 6, 12, 24, and $48 \mathrm{~h}$ and then measured using Cell Counting Kit-8. The viability percentage was determined from the absorbance ratio of the treated cells to the control cells $(n=4)$. (B) Vero cells were treated with various concentrations of $\mathrm{H}_{2} \mathrm{O}_{2}(0,100$, and $200 \mu \mathrm{M})$ for $1,2,4,6$, 12, and $24 \mathrm{~h}$. Intracellular ROS were determined using the Reactive Oxygen Species Detection Assay Kit, and ROS levels are expressed as the fold-change in fluorescence intensity in the test group compared with the untreated group. (C) Viability was measured for extracellular parasites (RH, TR-KO, ROP5-KO) treated with $200 \mu \mathrm{M} \mathrm{H}_{2} \mathrm{O}_{2}$ for 15, 30, 45, and 60 min; next, treated parasites were allowed to infect Vero cells. Vacuoles containing four or more parasites were measured and normalized to the number of untreated parasites incubated at the same time outside of the cell. (D) Parasites were treated with or without $\mathrm{H}_{2} \mathrm{O}_{2}(200 \mu \mathrm{M})$ after $12 \mathrm{~h}$ of infection. Parasite replication was quantified for the three strains by counting the number of parasites per vacuole and presented as the mean of parasites per vacuole. The replication assay for the treated group was compared to that for the untreated group. The results are presented as the mean \pm standard deviation of three (B,D), four (A), or five (C) independent experiments. ${ }^{\star *} P<0.01,{ }^{*} P<0.05$ significant changes versus control/RH strain.

viability in a dose- and time-dependent manner (Figure 1A). Cell viability was significantly reduced in the presence of high $\mathrm{H}_{2} \mathrm{O}_{2}$ concentrations $(400-800 \mu \mathrm{M})$ compared with that in the untreated group $(P<0.01$ or $P<0.05$, respectively). A significant decrease in cell viability was also observed after $12 \mathrm{~h}$ of treatment with $300 \mu \mathrm{M} \mathrm{H}_{2} \mathrm{O}_{2}(P<0.05)$. However, the viability of Vero cells treated with 100 or $200 \mu \mathrm{M} \mathrm{H}_{2} \mathrm{O}_{2}$ was not significantly affected within $24 \mathrm{~h}$ and remained higher than $88 \%$ after $48 \mathrm{~h}(91.6 \pm 13.34 \%, 88.81 \pm 6.51 \%)$. Therefore, these two $\mathrm{H}_{2} \mathrm{O}_{2}$ concentrations (100 and $\left.200 \mu \mathrm{M}\right)$ were used in subsequent experiments.

The intracellular ROS level was measured using a Reactive Oxygen Species Detection Assay Kit after 1, 2, 4, 6, 12, or $24 \mathrm{~h}$ of $\mathrm{H}_{2} \mathrm{O}_{2}$ treatment. The results revealed significantly increased ROS levels in the $200 \mu \mathrm{M} \mathrm{H}_{2} \mathrm{O}_{2}$ group after $2 \mathrm{~h}$; these levels were maintained at a high level throughout the experimental period $(P<0.01$ or $P<0.05$, respectively; Figure 1B). At $100 \mu \mathrm{M}$ $\mathrm{H}_{2} \mathrm{O}_{2}$, ROS levels were slightly increased compared with that in the control, but the differences were not significant $(P>0.05)$. Accordingly, $200 \mu \mathrm{M} \mathrm{H}_{2} \mathrm{O}_{2}$, which did not affect cell viability but significantly increased intracellular ROS levels, was used to construct the oxidative stress model for subsequent experiments.

To further determine the optimal incubation time of extracellular parasites with $\mathrm{H}_{2} \mathrm{O}_{2}(200 \mu \mathrm{M})$, the viability of the three T. gondii strains ( $\mathrm{RH}, \mathrm{ROP} 5-\mathrm{KO}$, and TR-KO) was evaluated by counting the number of vacuoles containing more than two parasites. The three strains showed differential sensitivity to $\mathrm{H}_{2} \mathrm{O}_{2}$; the viability of the $T R$ - $\mathrm{KO}$ strain was significantly inhibited $(P<0.01)$ after incubation with $\mathrm{H}_{2} \mathrm{O}_{2}$ for $30 \mathrm{~min}$, whereas the $\mathrm{RH}$ and $R O P 5-\mathrm{KO}$ strains were not susceptible to this condition. The inhibitory effect of $\mathrm{H}_{2} \mathrm{O}_{2}$ on the $\mathrm{RH}$ and $R O P 5-\mathrm{KO}$ strains began to increase after 45 min of incubation with $\mathrm{H}_{2} \mathrm{O}_{2}(P<0.01$ and $P<0.05$, respectively) (Figure 1C).

The number of parasites per vacuole was calculated to determine the inhibitory effect of $\mathrm{H}_{2} \mathrm{O}_{2}$ on intracellular parasite proliferation. Intracellular parasites were treated with $200 \mu \mathrm{M}$ $\mathrm{H}_{2} \mathrm{O}_{2}$ for $12 \mathrm{~h}$ post-invasion, and the number of parasites in each vacuole was counted $24 \mathrm{~h}$ after treatment. Compared with the untreated groups, $200 \mu \mathrm{M} \mathrm{H}_{2} \mathrm{O}_{2}$ significantly inhibited proliferation of the TR-KO strain $(P<0.01)$, whereas it did not affect replication of the $\mathrm{RH}$ and ROP5-KO strains or Vero cell growth (Figure 1D). Based on these results, the extracellular parasites were treated with $\mathrm{H}_{2} \mathrm{O}_{2}$ for $30 \mathrm{~min}$, and then $\mathrm{H}_{2} \mathrm{O}_{2}$ was added to the medium $12 \mathrm{~h}$ after infection and treated continuously until T. gondii naturally egressed from the cell, serving as the experimental setting for genomic screening. 


\section{Genome-Wide Screening to Identify Putative Antioxidant Genes in T. gondii}

Cas9-expressing $T$. gondii strains were selected and obtained with $40 \mathrm{mM}$ chloramphenicol. A diverse population of mutants was generated by transfecting a genome-wide sgRNA library containing 10 different sgRNAs against each of the 8,156 genes of this parasite into the Cas9-expressing $T$. gondii strains (RH/Cas9). Based on this mutant pool, loss-of-function screening was performed to select mutants that were susceptible to $\mathrm{H}_{2} \mathrm{O}_{2}$-mediated growth inhibition. This pool was propagated in the presence or absence of $200 \mu \mathrm{M} \mathrm{H} \mathrm{H}_{2} \mathrm{O}_{2}$ for three passages, and then, the relative abundance of sgRNAs was measured by Illumina sequencing using the DNA of untreated and treated parasites (Figures $2 \mathbf{A}, \mathbf{B}$ ). The $\log _{2}$-fold change of sgRNA between treated and control samples (screening score) was calculated and used to rank all genes (Figure 2C). The guides against CAT (TGGT1_232250) and TGGT1_217555 were among the most significantly depleted in the treated samples (Figures 2C,D). This analysis method has some shortcomings in that some sgRNAs (smaller number) are more likely to be lost and the screening scores in this method are lower. In genome-wide CRISPR/Cas9 screening experiments, sgRNA sequences targeting the same gene have different knockdown efficiencies. To ensure maximum loss percentage of at least one sgRNA targeting the same gene, sgRNAs were further ranked according to the loss percentage. A total of 30 sgRNAs with high knockout efficiency, large number of losses, and high loss proportion were selected by combining loss percentage $(>92 \%)$ and loss number $(>100)$ of sgRNA (Figure 2E). Among all genes, CAT (TGGT1_232250), TR (TGGT1_309730), and PRX3 (TGGT1_230410), which are important antioxidant genes, were selected, indicating that the $\mathrm{H}_{2} \mathrm{O}_{2}$-mediated oxidative stress model was successful and effective in selecting relevant genes involved in the antioxidant system of $T$. gondii, further proving the rationality of this selection method. Combined with phenotype score and screening score of the genes, five genes encoding hypothetical proteins, including TGGT1_217555 and the other four genes with low phenotype score and screening score, were selected for subsequent validation tests (Figure 2F). These genes, namely, HP1, HP2, HP3, HP4, and HP5, lacked functional annotation and respectively encoded previously unstudied T. gondii genes (Figure 2F).

\section{Identification of Genes Related to $\mathrm{H}_{2} \mathrm{O}_{2}$ Sensitivity}

To verify the antioxidant capacity and functionally characterize the candidate genes, HPs and CAT knockout strains were successfully constructed in the RH/Cas9 strains, and CAT-KO strain was used as a positive control. Next, the susceptibilities of wild-type $\mathrm{RH}$ and deletion strains to different $\mathrm{H}_{2} \mathrm{O}_{2}$ concentrations were evaluated by measuring the parasite viability, which was determined by counting the number of vacuoles containing more than two parasites after $36 \mathrm{~h}$ of culture. The results showed that with an increasing $\mathrm{H}_{2} \mathrm{O}_{2}$ concentration, the inhibition of $T$. gondii viability was enhanced, and the sensitivity of each knockout strain to $\mathrm{H}_{2} \mathrm{O}_{2}$ was increased to varying degrees compared to the $\mathrm{RH}$ strain. Particularly, the CAT-KO and HP1-KO mutants were the most sensitive to $\mathrm{H}_{2} \mathrm{O}_{2}$ stress. The HP3-KO strain also showed significantly increased sensitivity to $\mathrm{H}_{2} \mathrm{O}_{2}$ (Figure 3A). In addition, some parasites lacking CAT or HP1 were mostly unable to replicate, even if they were not immediately killed by $\mathrm{H}_{2} \mathrm{O}_{2}$.

Next, the effect of $\mathrm{H}_{2} \mathrm{O}_{2}$ on the replication ability of intracellular parasites was assessed by counting the number of parasites in each vacuole of the $\mathrm{RH}$ and mutant strains grown in the presence of $200 \mu \mathrm{M} \mathrm{H}_{2} \mathrm{O}_{2}$. Overall, the replication ability of each mutant was significantly decreased compared with that of the RH strain $(P<0.01)$. Among these knockout strains, the inhibitory effect of $\mathrm{H}_{2} \mathrm{O}_{2}$ on the replication ability of the HP1-KO and CAT-KO strains was more significant and higher than $70 \%$ for vacuoles containing only one or two parasites (Figures 3B,C). These results revealed that $\mathrm{H}_{2} \mathrm{O}_{2}$ significantly inhibited the intracellular replication of deletion strains and that the inhibitory effect of $\mathrm{H}_{2} \mathrm{O}_{2}$ was most obvious for the HP1-KO and $C A T-\mathrm{KO}$ strains.

\section{ROS, T-AOC, and MDA Levels in T. gondii Mutants and ROS Levels in Mouse Macrophages}

As determined by the DCFH-DA assay, the ROS levels in mutants were higher than those in wild-type $\mathrm{RH}$, with the levels in the CAT-KO and HP1-KO strains significantly higher than those in wild-type RH $(P<0.01)$ (Figure 4A). Similarly, the levels of MDA in all mutants were elevated; MDA levels in the CAT$\mathrm{KO}, H P 1-\mathrm{KO}, H P 2-\mathrm{KO}$, and HP4-KO strains were significantly higher than those in wild-type $\mathrm{RH}(P<0.01$ or $P<0.05)$ (Figure 4C). Similarly, T-AOC levels in mutants were lower than those in wild-type $\mathrm{RH}$, with significant differences detected between the CAT-KO, HP1-KO, and HP2-KO strains and wildtype RH $(P<0.05)$ (Figure 4B). These results suggest that CAT and HP1 are critical for the antioxidant system of T. gondii. Furthermore, the effects of infection by CAT-KO, HP1-KO, and $\mathrm{RH}$ strains on ROS production in mouse macrophages at a 2:1 ratio (tachyzoite: macrophages) were observed. The results showed that ROS levels in macrophages infected with the three strains increased significantly throughout the experimental period. Moreover, ROS levels in macrophages first increased and then tended to decrease with prolonged culture time. Particularly, ROS levels in macrophages infected with CAT-KO and HP1-KO peaked at $12 \mathrm{~h}$, and there was a significant difference in ROS levels in macrophages infected with $C A T-\mathrm{KO}, H P 1-\mathrm{KO}$, and wild-type RH strains at 12 and $24 \mathrm{~h}(P<0.01$ or $P<0.05$; Figure $4 \mathrm{D})$. The results indicate that CAT and HP1 deletion affects ROS production in $T$. gondii-infected macrophages.

\section{Phenotypic Analyses of HP-KO Strains}

The invasion capacity of HP-KO strains was determined by flow cytometry after $12 \mathrm{~h}$ of culture. The mutants showed different degrees of reduced invasiveness and invasion efficiency, which were significantly lower in HP1-KO and HP3-KO strains than in the wild-type $\mathrm{RH}(P<0.05$; Figure 5A). Moreover, the average number of parasites per vacuole of all mutant strains 
A

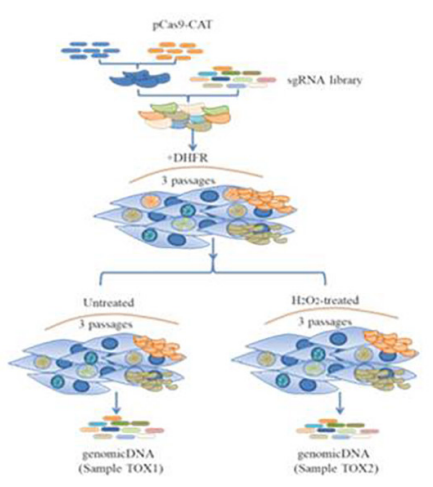

C

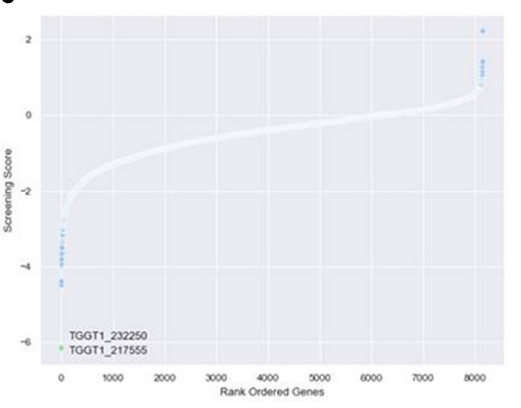

B

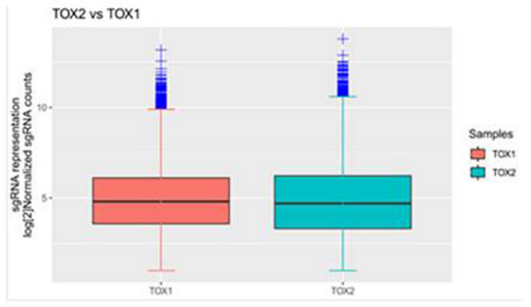

D

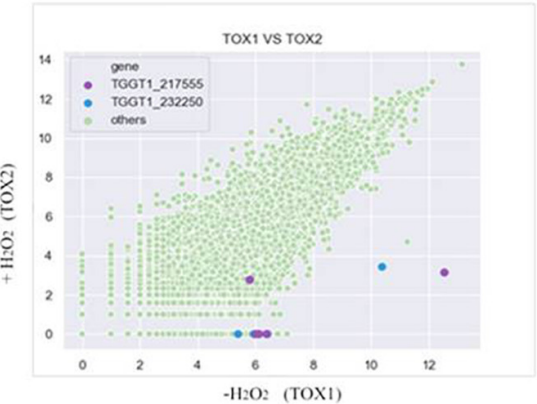

E

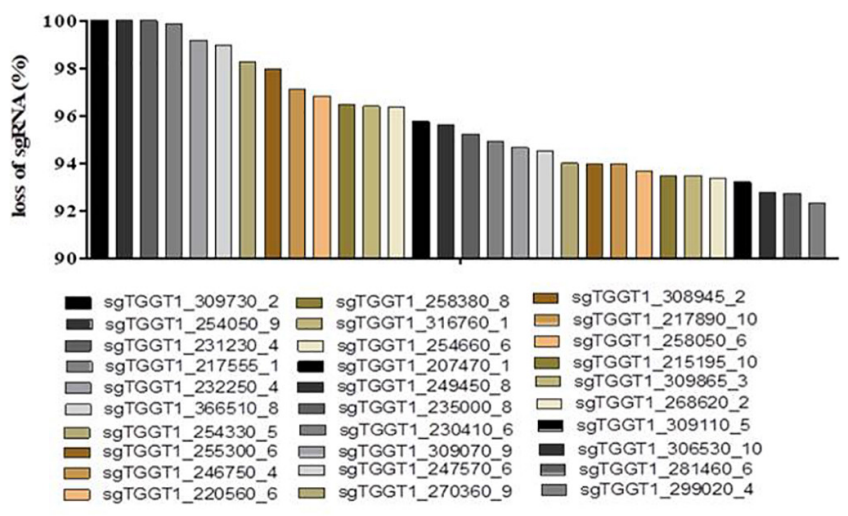

$\mathbf{F}$

\begin{tabular}{cc}
\hline \multicolumn{1}{c}{ Name } & Gene ID \\
\hline hypothetical protein 1 (HP1) & TGGT1_217555 \\
\hline hypothetical protein 2 (HP2) & TGGT1_255300 \\
\hline hypothetical protein 3 (HP3) & TGGT1_316760 \\
\hline hypothetical protein 4 (HP4) & TGGT1_249450 \\
hypothetical protein 5 (HP5) & TGGT1_309070 \\
\hline
\end{tabular}

FIGURE 2 | Genome-wide screen identifies mutants hypersensitive to $\mathrm{H}_{2} \mathrm{O}_{2}$. (A) Workflow of the genome-wide screen. RH/Cas9 parasites were transfected with a library of sgRNAs. Transfected parasites were grown in Vero cells and selected by pyrimethamine. Subsequently, the mutants were either treated with $\mathrm{H}_{2} \mathrm{O}_{2}$ for three passages or continuously passaged in Vero cells. SgRNA was sequenced and analyzed to select genes related to $\mathrm{H}_{2} \mathrm{O}_{2}$ sensitivity. (B) Boxplot showing the distribution of sgRNA frequencies before and after $\mathrm{H}_{2} \mathrm{O}_{2}$ treatment. (C) Toxoplasma gondii genes were ordered according to their screening scores, which is defined as the mean $\log _{2}$-fold-change of the top five most abundant sgRNA for each gene in the control sample. A lower score indicates that the sensitivity of mutants to $\mathrm{H}_{2} \mathrm{O}_{2}$ increases when the gene is deleted. Guides against TGGT1_217555 and CAT were significantly depleted upon $\mathrm{H}_{2} \mathrm{O}_{2}$ treatment. (D) Scatter plots representing the relative abundance of sgRNAs in the untreated sample and $\mathrm{H}_{2} \mathrm{O}_{2}$-treated sample; sgRNAs against TGGT1_232250 (blue); sgRNAs against TGGT1_217555 (purple). (E) The top 30 candidate genes were selected according to the percentage of lost sgRNA. (F) List of selected putative antioxidant genes numbered according to the percentage of lost sgRNA from highest (HP1) to lowest (HP5). 

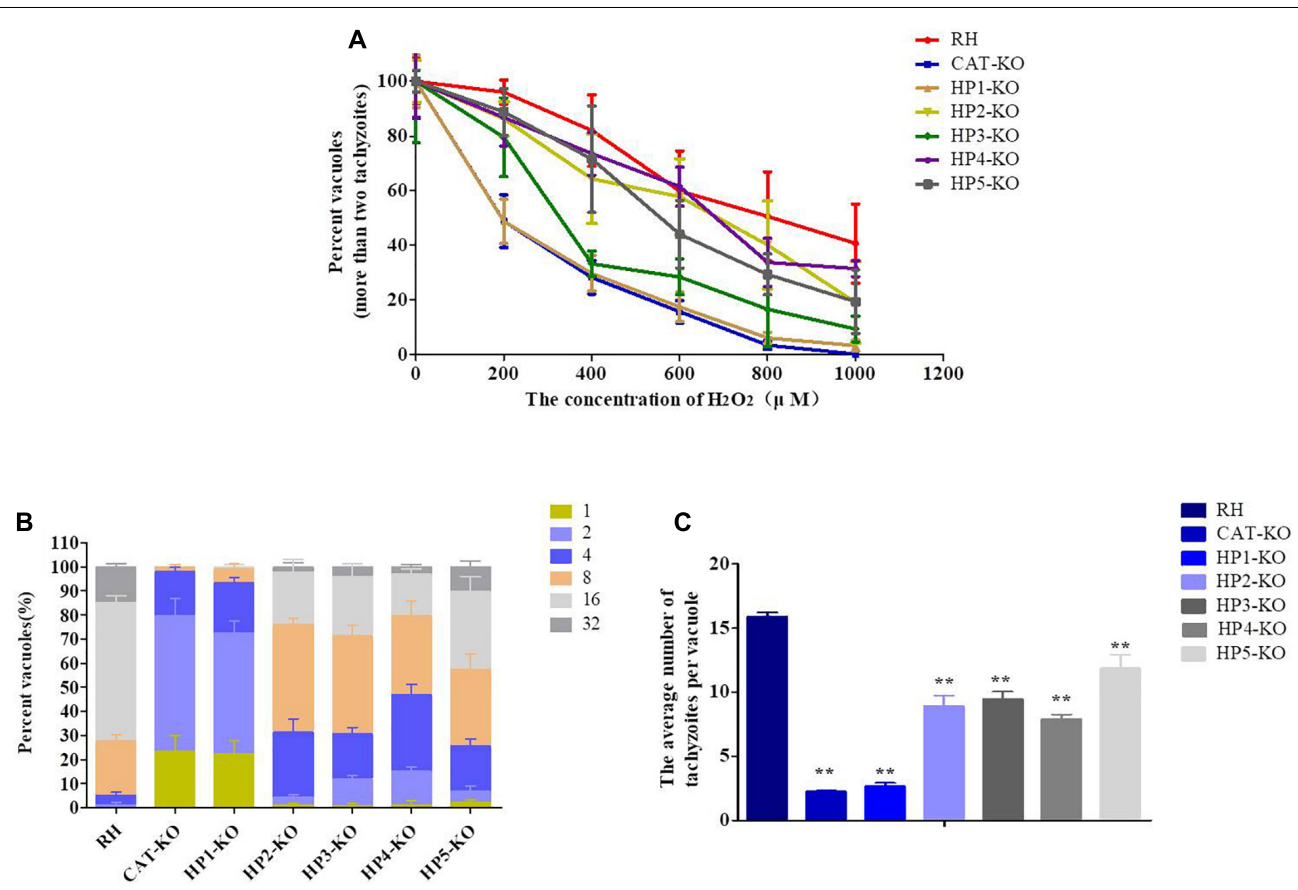

FIGURE 3 | Effect of $\mathrm{H}_{2} \mathrm{O}_{2}$ on knockout parasites and $\mathrm{RH}$ strain. (A) Effect of $\mathrm{H}_{2} \mathrm{O}_{2}$ on the viability of T. gondii parental and knockout strains. Fresh tachyzoites of different strains were incubated for 30 min in the presence of the indicated $\mathrm{H}_{2} \mathrm{O}_{2}$ concentrations. The treated parasites were inoculated on Vero cells. The number of vacuoles was counted under a microscope at $36 \mathrm{~h}$ after infection. Data are expressed as a percentage (\%) of the number of vacuoles formed by the treated groups compared to the untreated group. (B,C) At $12 \mathrm{~h}$ post-infection with tachyzoites, the cells were cultured in a medium containing $200 \mu \mathrm{M} \mathrm{H}_{2} \mathrm{O}_{2}$. The effect of $\mathrm{H}_{2} \mathrm{O}_{2}$ on parasite replication was assessed by calculating the number of tachyzoites in each vacuole after $36 \mathrm{~h}$ of infection for a minimum of 100 vacuoles per strain. (B) Data are expressed as the percentage of vacuoles containing 1, 2, 4, 8, 16, and 32 parasites. (C) Data are expressed as the average number of parasites per vacuole. Data are represented as the mean \pm standard deviation $(n=4)$. ${ }^{\star \star} P<0.01,{ }^{\star} P<0.05$, significant changes versus controls.

was significantly lower than that of wild-type $\mathrm{RH}(P<0.01$ or $P<0.05$ ) (Figures 5B,C). Next, plaque assays were performed with all mutants on a monolayer of Vero cells to assess parasite viability and competency over several lytic cycles. All HP-KO strains had varying degrees of reduced plaque formation, and the plaques formed were smaller than those of the wild-type $\mathrm{RH}$ strain, indicating a growth defect (Figure 6A). Comparatively, both CAT-KO and HP3-KO showed a significant reduction in plaque formation (Figure 6B). The plaque assays were repeated under $\mathrm{H}_{2} \mathrm{O}_{2}$ conditions (medium supplemented with $200 \mu \mathrm{M} \mathrm{H}_{2} \mathrm{O}_{2}$ ), in which all mutants formed plaques significantly smaller than those of the wild-type $\mathrm{RH}$ strain, and the plaque formation potential in the mutants was significantly reduced (Figures 6A,C). These results revealed that deletion of HPs and $C A T$ affected parasite proliferation and led to growth defects. Furthermore, the inhibitory effect of $\mathrm{H}_{2} \mathrm{O}_{2}$ on the growth of the $H P$-KO strains was greater than that of the wild-type $\mathrm{RH}$ strain. This was particularly noticeable for the CAT-KO and HP1$\mathrm{KO}$ strains. This finding was consistent with the increase in the ROS levels in mutant strains, further proving that these genes are related to the antioxidant activity of T. gondii.

\section{Effect of HP Mutants on T. gondii Virulence}

Previous studies showed that deletion of the antioxidant-related genes of $T$. gondii, including $T R$ and $C A T$, attenuated virulence in mice (Ding et al., 2004; Xue et al., 2017). Therefore, we evaluated the influence of $H P$ deletion on the virulence of the $\mathrm{RH}$ strain. Eight-week-old Kunming mice (10 mice/group) were injected with purified tachyzoites of wild-type RH, CAT-KO, or HP-KO strains. The survival rates of all mice are shown in Figure 7. Mice inoculated with the $\mathrm{RH}$ strain died within 7 days, while mice infected with knockout strains had extended survival times. Remarkably, the survival times of mice infected with the CAT$\mathrm{KO}$ and HP1-KO strains was significantly longer than those of mice infected with wild-type $\mathrm{RH}$, which died within 7 days of inoculation $(P<0.01$; Figure 7$)$. These results indicated that $C A T$ or HP1 disruption led to weakened virulence of the parasite.

\section{DISCUSSION}

In the current study, genome-wide loss-of-function screening was performed to identify Toxoplasma genes that determine fitness in an $\mathrm{H}_{2} \mathrm{O}_{2}$-induced oxidative stress environment in vitro. Evading oxidative damage caused by host ROS is essential for T. gondii to establish acute or chronic infection (Arsenijevic et al., 2001; Zhu et al., 2019). As shown in our previous study that TR in T. gondii is an essential virulence effector with antioxidant function, which is critical for parasite growth and survival (Xue et al., 2017). Moreover, in-depth studies of T. gondii antioxidant-related genes may provide a theoretical 

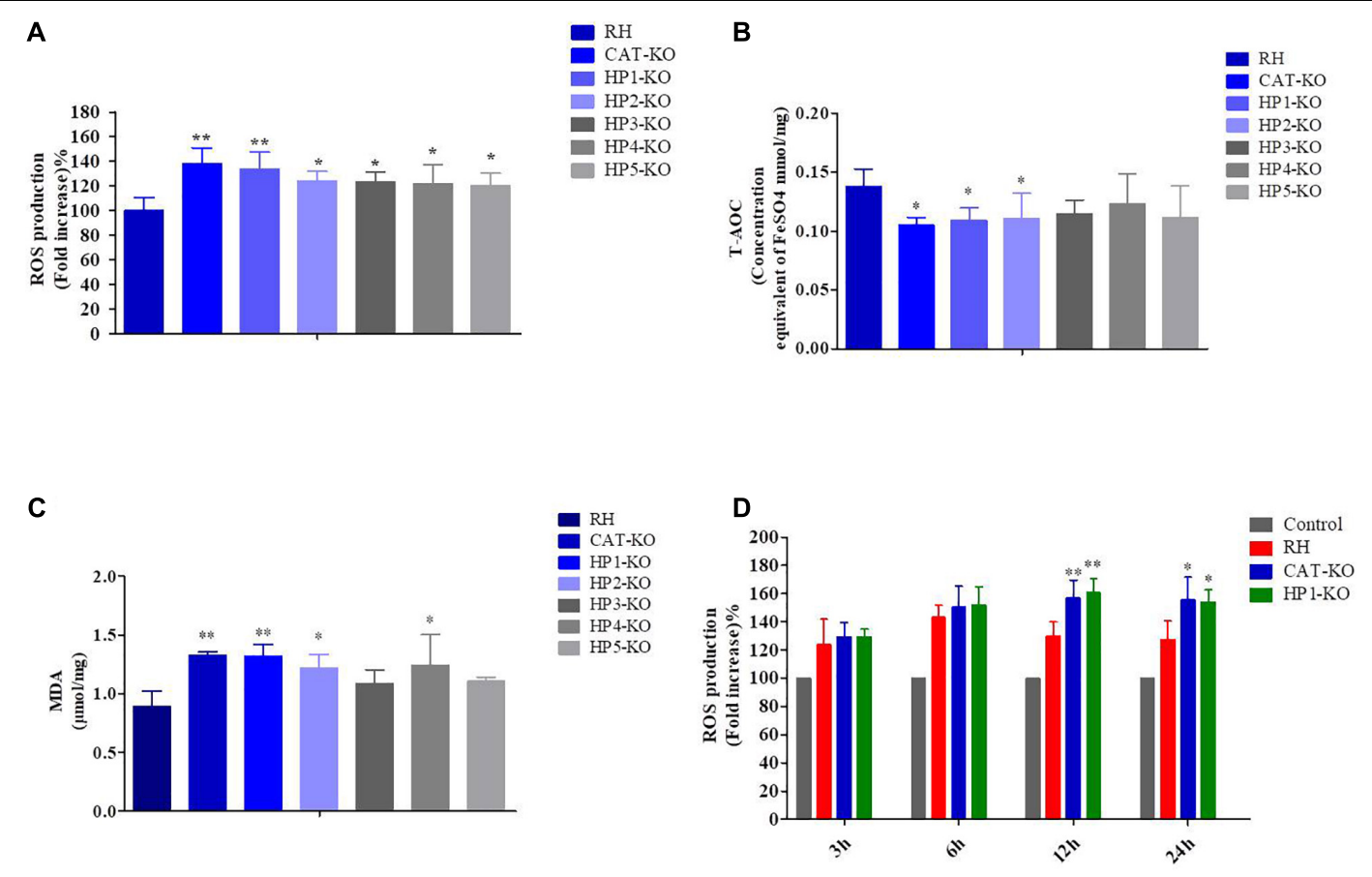

FIGURE 4 | Reactive oxygen species (ROS), total antioxidant capability (T-AOC), and malondialdehyde (MDA) levels in Toxoplasma gondii and reactive oxygen species levels in macrophages. (A) ROS levels in tachyzoites. Data are expressed as a percentage (\%) of the ROS level of mutants compared to the ROS level in RH parasites. (B) T-AOC and (C) MDA levels in tachyzoites. All samples were measured in triplicates. (D) ROS levels in macrophages. Data are expressed as a percentage (\%) of ROS levels in mutant-infected macrophages compared to that in control macrophages. All samples were measured in triplicates. ${ }^{* \star} P<0.01$, ${ }^{*} P<0.05$ significant changes versus control/RH strain.
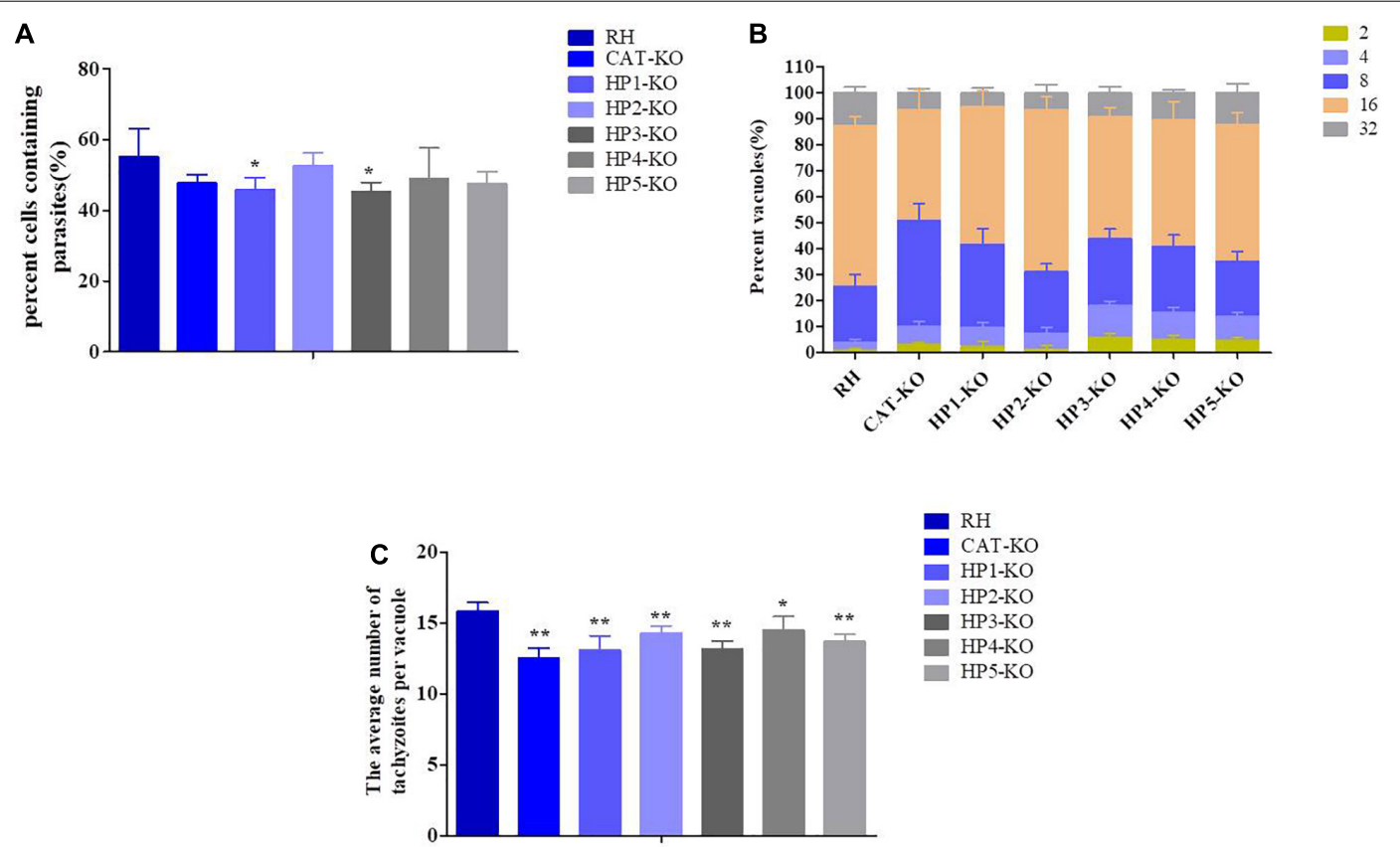

FIGURE 5 | Invasiveness and proliferative potential of hypothetic protein (HP)-knockout (KO) Toxoplasma gondii strains. (A) Invasiveness potential of HP-KO strains. (B,C) Parasite replication was assessed by calculating the number of tachyzoites in each vacuole after $36 \mathrm{~h}$ of infection for a minimum of 100 vacuoles per strain. Data are represented as the mean \pm standard deviation $(n=4) .{ }^{* \star} P<0.01,{ }^{*} P<0.05$, significant changes versus controls. 

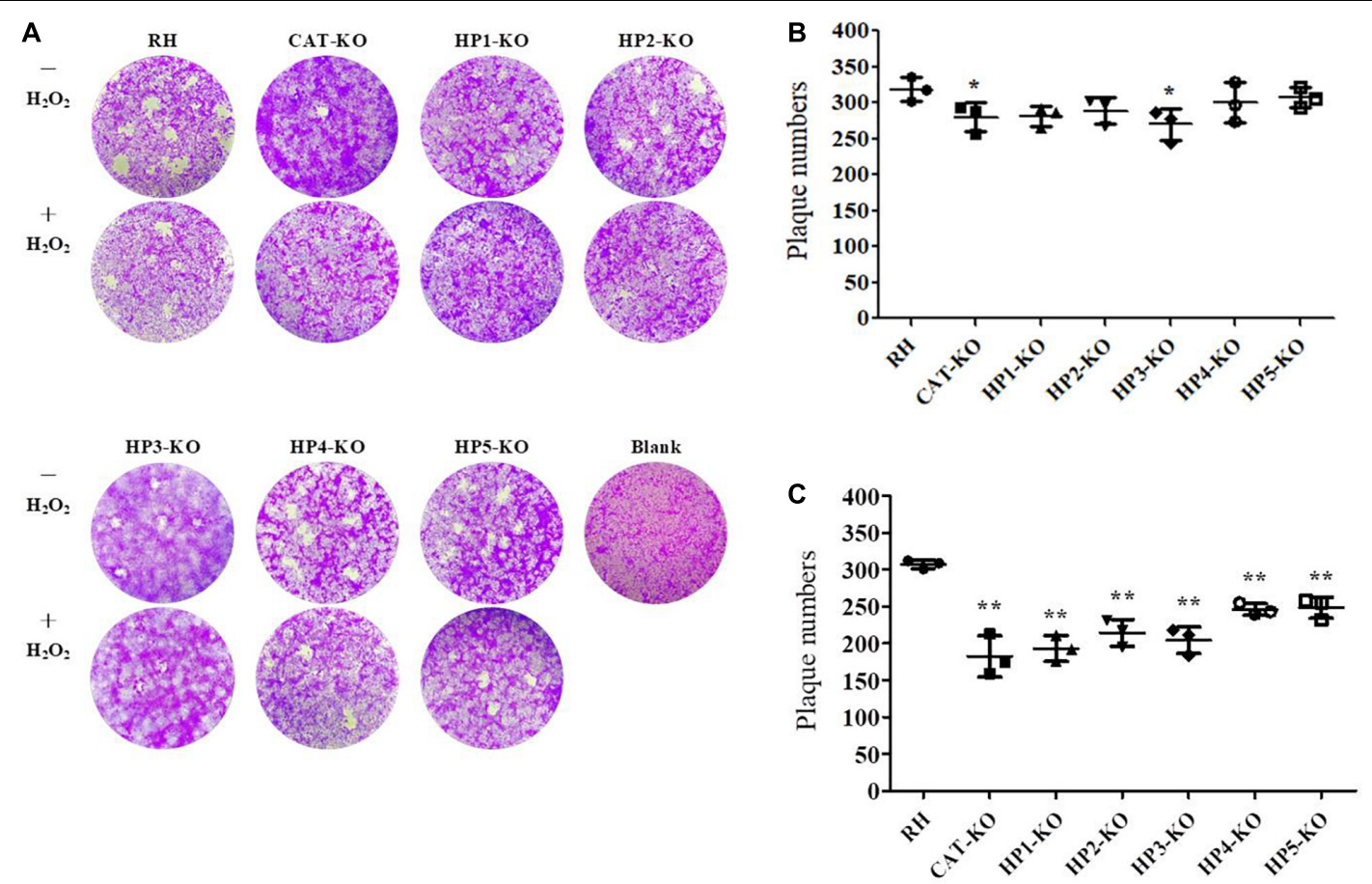

FIGURE 6 | Plaque assays. Vero cells were infected with 500 tachyzoites of each strain and cultured for 7 days. In addition, treated groups were added to $\mathrm{H}_{2} \mathrm{O}_{2}$-containing medium at $12 \mathrm{~h}$ after infection, which was replaced with a normal medium at $48 \mathrm{~h}$ after infection. After 7 days, plaques were stained with crystal violet and photographed. (A) Representative images (magnification: $\times 100$ ). (B) Plaques formed under normal culture conditions. (C) Plaques formed under $\mathrm{H}_{2} \mathrm{O}_{2}$ culture conditions. Data for the mutants were compared to the wild-type $\mathrm{RH}$ strain.

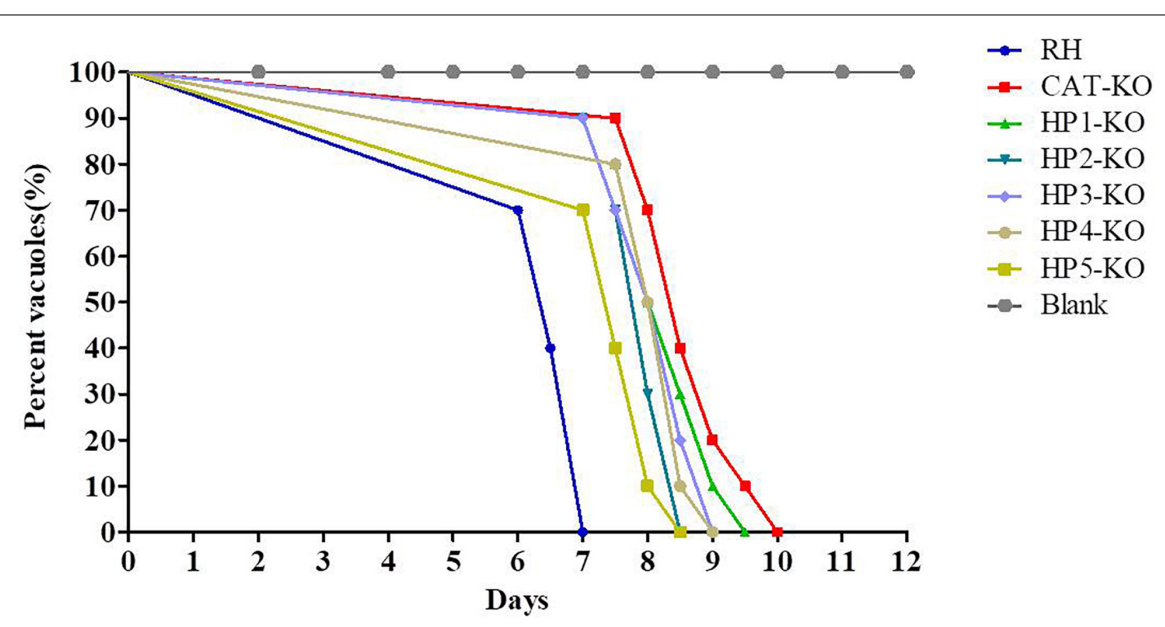

FIGURE 7 | Effect of hypothetic protein (HP)-knockout (KO) on Toxoplasma gondii virulence. Kunming mice (10 mice/group) were intraperitoneally injected with $1 \times 10^{3}$ parasites of $\mathrm{KO}$ strains or $\mathrm{RH}$ strain of $T$. gondii, and the survival time of mice was monitored for 12 days.

basis for developing anti-T. gondii drugs because some currently available drugs (such as monensin, mefloquine, and artemisinin) that induce ROS production and target the antioxidant system have been shown to be effective against $T$. gondii and/or Plasmodium (Berens et al., 1998; Charvat and Arrizabalaga, 2016; Gunjan et al., 2016; Zhai et al., 2020). Therefore, identification parasite antioxidant genes is important for understanding the mechanisms of $T$. gondii in eliminating ROS, as well as for identifying useful targets for anti-Toxoplasma drugs, and this requires further investigations.

Reactive oxygen species consist of $\mathrm{O}_{2}{ }^{-}, \mathrm{H}_{2} \mathrm{O}_{2}$, hydroxyl radical, and ozone (Yang et al., 2020). Being the most stable ROS element, $\mathrm{H}_{2} \mathrm{O}_{2}$ can stimulate the production of endogenous ROS and trigger oxidative damage (Jakovljević et al., 2018). Coincubation of $T$. gondii mutants with $\mathrm{H}_{2} \mathrm{O}_{2}$ is a strategy for determining whether genes are associated with resistance to ROS 
(Ding et al., 2004). Herein, $\mathrm{H}_{2} \mathrm{O}_{2}$ was further added to the cell culture medium to enhance the inhibitory effect of $\mathrm{H}_{2} \mathrm{O}_{2}$ on intracellular T. gondii. The results revealed no significant effect on the cells or the T. gondii $\mathrm{RH}$ strain at $200 \mu \mathrm{M} \mathrm{H}_{2} \mathrm{O}_{2}$, but a significant inhibitory effect on the viability and proliferation of TR-KO was noted. This is consistent with the findings of our previous study (Xue et al., 2017). Based on this optimal experimental setting, some genes for which sgRNA numbers were remarkably decreased upon $\mathrm{H}_{2} \mathrm{O}_{2}$ treatment were selected. CAT, $T R$, and $P R X 3$, associated with ROS resistance (Ding et al., 2004; Xue et al., 2017), were among the identified genes, demonstrating that our $\mathrm{H}_{2} \mathrm{O}_{2}$-mediated oxidative stress screening is a useful approach for identifying ROS-related genes.

Five candidate genes (TGGT1_217555, TGGT1_255300, TGGT1_316760, TGGT1_249450, and TGGT1_309070), showing significantly reduced sgRNA levels upon $\mathrm{H}_{2} \mathrm{O}_{2}$ stimulation, were further investigated. Upon genetic disruption of each HP- and CAT-encoding gene, $\mathrm{H}_{2} \mathrm{O}_{2}$ markedly inhibited the viability and proliferation of the parasites. In addition, increased levels of ROS and MDA and the reduced level of T-AOC in HP-KO strains further indicated that these HPs are associated with the antioxidant capacity of $T$. gondii. Moreover, the higher sensitivity of $\mathrm{HP1-KO}$ to $\mathrm{H}_{2} \mathrm{O}_{2}$ was similar to that of $C A T-\mathrm{KO}$, suggesting that $\mathrm{HP} 1$ function is critical for resisting ROS. When the activity of antioxidant enzymes, such as CAT, is reduced, the susceptibility of the parasites to oxidative stress increases, and $\mathrm{H}_{2} \mathrm{O}_{2}$-induced ROS can disrupt the redox balance in the parasite, leading to dysfunction of the antioxidant defense and consequent DNA damage, protein damage, or death of the parasite (Shojaee et al., 2014; Lin et al., 2016). Monocytes/macrophages are involved in the defense against intracellular T. gondii by upregulating ROS levels (Yamashita et al., 1998; Hunter and Sibley, 2012). We also found that ROS levels in macrophages infected with $H P 1-\mathrm{KO}$ strain were higher than those infected with $\mathrm{RH}$ strain, which may increase the inhibitory effect of macrophages on HP1-KO strain. However, the mechanisms that lead to increased ROS levels need further research.

Additional experiments demonstrated that the invasion and proliferation abilities of each HP-KO strain were decreased compared with those of the wild-type strain and that virulence in mice was attenuated, and the survival time of mice infected with the HP-KO and CAT-KO strains was longer than that of mice infected with the $\mathrm{RH}$ strain. These results suggest that HPs are important for the growth of tachyzoites. Plaque assays further indicated that HP disruption caused growth defects of parasites, forming smaller plaques. However, each HP-KO strain could be independently grown in normal culture. Further, the virulence of mutants was not completely lost, suggesting that the complex antioxidant mechanisms that involve the interaction between several proteins and molecules, as well as with other antioxidant gene, can confer protection against endogenous oxidative damage. Indeed, SOD2 and a thioredoxin peroxidase found in the apicoplast can eliminate ROS, and PRX1, PRX2, and PRX3 act downstream of SODs to detoxify $\mathrm{H}_{2} \mathrm{O}_{2}$ (Ding et al., 2004; Pino et al., 2007). In Plasmodium falciparum, the glutathione and thioredoxin systems are the two main branches of redox homeostasis regulation, with functional complementation between these systems possibly compensating for the lack of some key antioxidant proteins (Chaudhari et al., 2017).

Furthermore, parasites lacking HP1 were more sensitive to externally applied $\mathrm{H}_{2} \mathrm{O}_{2}$ than other $H P$-KO strains, suggesting that HP1 plays an important role in regulating oxidative stress. The precise role of HP1 in T. gondii requires further analysis. To date, HP1 is a completely unknown protein with a molecular mass of $11.6 \mathrm{kDa}$. No signal peptides or known structural domains were found in this protein. HP1 homologs are only found in Aconoidasida and Coccidia. Only $32 \%$ of HP1 transcripts matched with glucose 6phosphate dehydrogenase (G6PDH) assembly protein (OpcA) of Synechococcus elongatus in the UniProtKB/Swiss-Prot database (details are provided in Supplementary Figure 2). OpcA was reported to be involved in oligomerization and activation of G6PDH. In addition, some thioredoxin regulate G6PDH activity by a change in the OpcA redox status (Özkul and Karakaya, 2015; Mihara et al., 2018). G6PDH is necessary for enhancing the activity of antioxidant enzymes and regulating NADPH provision. Earlier studies found that the G6PDH activity of Trypanosoma cruzi was markedly increased under $\mathrm{H}_{2} \mathrm{O}_{2}$ stress (Igoillo-Esteve and Cazzulo, 2006). Additional studies to evaluate the molecular machinery of HP1 by transcriptome sequencing and protein interaction analysis are needed.

\section{CONCLUSION}

In conclusion, our study demonstrated that the CRISPR/Cas9 system can be used to identify potential genes involved in oxidative stress response in T. gondii. Functional characterization of five hypothetical genes was performed. Our results indicate that HP1 plays an important role in the defense against oxidative damage and can be considered a virulence factor associated with T. gondii infection. These results provide broad-based functional information on $T$. gondii genes related to oxidative stress and will facilitate future studies to expand the landscape of antiparasitic interventions.

\section{DATA AVAILABILITY STATEMENT}

The datasets presented in this study can be found in online repositories. The names of the repository/repositories and accession number(s) can be found below: https://www.ncbi.nlm. nih.gov/, PRJNA707360.

\section{ETHICS STATEMENT}

The animal study was reviewed and approved by the Institutional Animal Care and Use Committee of the Shanghai Veterinary Research Institute. 


\section{AUTHOR CONTRIBUTIONS}

YC, J-XX, QW, and WJ designed the research. YC, QL, and QW performed the research. YC, QW, WJ, X-LG, and M-YZ analyzed the data. YC, QL, and WJ wrote the manuscript. All authors contributed to the article and approved the submitted version.

\section{FUNDING}

This work was supported by the National Key Research and Development Programs of China (no. 2016YFD0501101), the Shanghai Science and Technology Promotion Agriculture Innovation Program (2019No.3-3), and Science and Technology Development Fund of Pudong New Area (PKJ2019-N09).

\section{REFERENCES}

Aline, F., Bout, D., and Dimier-Poisson, I. (2002). Dendritic Cells as Effector Cells: Gamma Interferon Activation of Murine Dendritic Cells Triggers OxygenDependent Inhibition of Toxoplasma gondii Replication. Infect Immun. 70, 2368-2374. doi: 10.1128/iai.70.5.2368-2374.2002

Arsenijevic, D., Bilbao, F. D., Giannakopoulos, P., Girardier, L., Samec, S., and Richard, D. (2001). A role for interferon-gamma in the hypermetabolic response to murine toxoplasmosis. Eur Cytokine Netw. 12, 518-527.

Behnke, M. S., Fentress, S. J., Mashayekhi, M., Li, L. X., Taylor, G. A., and Sibley, L. D. (2012). The Polymorphic Pseudokinase ROP5 Controls Virulence in Toxoplasma gondii by Regulating the Active Kinase ROP18. PLoS Pathog. 8:e1002992. doi: 10.1371/journal.ppat.1002992

Berens, R. L., Krug, E. C., Nash, P. B., and Curiel, T. J. (1998). Selection and characterization of Toxoplasma gondii mutants resistant to artemisinin. J Infect Dis. 177, 1128-1131. doi: 10.1086/517411

Blader, I. J., and Saeij, J. P. (2009). Communication between Toxoplasma gondii and its host: Impact on parasite growth, development, immune evasion, and virulence. Apmis 117, 458-476. doi: 10.1111/j.1600-0463.2009.02453

Boczoń, K. (2002). Pierwsze badania peroksydoksyn-nowej rodziny antyoksydantów u pasozytów [The data from the first investigations of a new antioxidants family-peroxidoxins-in parasites]. Wiad Parazytol 48, 3-10.

Charvat, R. A., and Arrizabalaga, G. (2016). Oxidative stress generated during monensin treatment contributes to altered Toxoplasma gondii mitochondrial function. Sci Rep. 6, 22997. doi: 10.1038/srep22997

Chaudhari, R., Sharma, S., and Patankar, S. (2017). Glutathione and thioredoxin systems of the malaria parasite Plasmodium falciparum: Partners in crime? Biochem Biophys Res Commun. 488, 95-100. doi: 10.1016/j.bbrc.2017.05.015

Dincel, G. C., and Atmaca, H. T. (2016). Role of oxidative stress in the pathophysiology of Toxoplasma gondii infection. Int J Immunopathol Pharmacol. 29, 226-240. doi: 10.1177/0394632016638668

Ding, M., Kwok, L. Y., Schlüter, D., Clayton, C., and Soldati, D. (2004). The antioxidant systems in Toxoplasma gondii and the role of cytosolic catalase in defence against oxidative injury. Mol Microbiol. 51, 47-61. doi: 10.1046/j.13652958.2003.03823.x

Fukai, T., and Ushio-Fukai, M. (2011). Superoxide dismutases: role in redox signaling, vascular function, and diseases. Antioxid Redox Signal. 15, 15831606. doi: 10.1089/ars.2011.3999

Gay, G., Braun, L., Brenier-Pinchart, M. P., Vollaire, J., Josserand, V., Bertini, R. L., et al. (2016). Toxoplasma gondii TgIST co-opts host chromatin repressors dampening STAT1-dependent gene regulation and IFN- $\gamma$-mediated host defenses. J Exp Med. 213, 1779-1798. doi: 10.1084/jem.20160340

Gunjan, S., Singh, S. K., Sharma, T., Dwivedi, H., Chauhan, B. S., Imran Siddiqi, M., et al. (2016). Mefloquine induces ROS mediated programmed cell death in malaria parasite: Plasmodium. Apoptosis. 21, 955-964. doi: 10.1007/s10495016-1265-y

Han, J., Perez, J. T., Chen, C., Li, Y., Benitez, A., Kandasamy, M., et al. (2018). Genome-wide CRISPR/Cas9 Screen Identifies Host Factors Essential for

\section{SUPPLEMENTARY MATERIAL}

The Supplementary Material for this article can be found online at: https://www.frontiersin.org/articles/10.3389/fmicb. 2021.670705/full\#supplementary-material

Supplementary Figure 1 | PCR validation of CAT- and hypothetical protein (HP)-KO parasites.

Supplementary Figure 2 | Bioinformatics analysis of hypothetical protein HP1.

Supplementary Table 1 | Primers used in this study.

Supplementary Table 2 | Information on the 30 genes selected in the analyses.

Supplementary Data Sheet 1 | Raw sgRNA read counts and analysis of sgRNA sequencing data.

Influenza Virus Replication. Cell Rep. 23, 596-607. doi: 10.1016/j.celrep.2018. 03.045

Hermanns, T., Müller, U. B., Könen-Waisman, S., Howard, J. C., and Steinfeldt, T. (2016). The Toxoplasma gondii rhoptry protein ROP18 is an Irga6-specific kinase and regulated by the dense granule protein GRA7. Cell Microbiol. 18, 244-259. doi: 10.1111/cmi.12499

Hunter, C. A., and Sibley, L. D. (2012). Modulation of innate immunity by Toxoplasma gondii virulence effectors. Nat Rev Microbiol. 10, 766-778. doi: $10.1038 /$ nrmicro2858

Igoillo-Esteve, M., and Cazzulo, J. J. (2006). The glucose-6-phosphate dehydrogenase from Trypanosoma cruzi: its role in the defense of the parasite against oxidative stress. Mol Biochem Parasitol. 149, 170-181. doi: 10.1016/j.molbiopara.2006.05.009

Jakovljević, K., Joksović, M. D., Matić, I. Z., Petrović, N., Stanojković, T., Sladić, D., et al. (2018). Novel 1,3,4-thiadiazole-chalcone hybrids containing catechol moiety: synthesis, antioxidant activity, cytotoxicity and DNA interaction studies. Medchemcomm. 9, 1679-1697. doi: 10.1039/c8md00316e

Kaasch, A. J., and Joiner, K. A. (2015). Targeting and subcellular localization of Toxoplasma gondii catalase. Identification of peroxisomes in an apicomplexan parasite. J Biol Chem. 275, 1112-1118. doi: 10.1074/jbc.275.2.1112

Kapoor, G., and Banyal, H. S. (2009). Glutathione reductase and thioredoxin reductase: novel antioxidant enzymes from Plasmodium berghei. Korean J Parasitol. 47, 421-424. doi: 10.3347/kjp.2009.47.4.421

Kim, J. H., Lee, J., Bae, S. J., Kim, Y., Park, B. J., Choi, J. W., et al. (2017). NADPH oxidase 4 is required for the generation of macrophage migration inhibitory factor and host defense against Toxoplasma gondii infection. Sci Rep. 7, 6361. doi: 10.1038/s41598-017-06610-4

Lajarin, F., Rubio, G., Lorenzo, N., Gámiz, P., Hernandez-Caselles, T., and GarciaPeñarrubia, P. (1999). Implication of reactive oxygen species in the antibacterial activity against Salmonella typhimurium of hepatocyte cell lines. Free Radic Biol Med. 27, 1008-1018. doi: 10.1016/s0891-5849(99)00148-3

Lin, X., Wu, S., Wang, Q., Shi, Y., Liu, G., Zhi, J., et al. (2016). Saikosaponin-D Reduces H2O2-Induced PC12 Cell Apoptosis by Removing ROS and Blocking MAPK-Dependent Oxidative Damage. Cell Mol Neurobiol. 36, 1365-1375. doi: 10.1007/s10571-016-0336-5

MacMicking, J. D. (2012). Interferon-inducible effector mechanisms in cellautonomous immunity. Nat Rev Immunol. 12, 367-382. doi: 10.1038/nri3210

Mihara, S., Wakao, H., Yoshida, K., Higo, A., Sugiura, K., Tsuchiya, A., et al. (2018). Thioredoxin regulates G6PDH activity by changing redox states of OpcA in the nitrogen-fixing cyanobacterium Anabaena sp. PCC 7120. Biochem J. 475, 1091-1105. doi: 10.1042/BCJ20170869

Murray, H. W., Rubin, B. Y., Carriero, S. M., and Harris, A. M. (1985). Human mononuclear phagocyte antiprotozoal mechanisms: oxygen-dependent vs oxygen-independent activity against intracellular Toxoplasma gondii. $J$ Immunol. 134, 1982-1988.

Ong, Y. C., Reese, M. L., and Boothroyd, J. C. (2010). Toxoplasma rhoptry protein 16 (ROP16) subverts host function by direct tyrosine phosphorylation of STAT6. J Biol Chem. 285, 28731-28740. doi: 10.1074/jbc.M110.112359 
Özkul, K., and Karakaya, H. (2015). Characterisation of an opcA Mutant of the Unicellular Cyanobacterium Synechocystis sp. PCC 6803. Curr Microbiol. 71, 572-578. doi: 10.1007/s00284-015-0889-4

Packialakshmi, B., and Zhou, X. (2018). Experimental autoimmune encephalomyelitis (EAE) up-regulates the mitochondrial activity and manganese superoxide dismutase (MnSOD) in the mouse renal cortex. PLoS One. 13:e0196277. doi: 10.1371/journal.pone.0196277

Padín-Irizarry, V., Colón-Lorenzo, E. E., Vega-Rodríguez, J., Castro, M. R., González-Méndez, R., Ayala-Peña, S., et al. (2016). Glutathione-deficient Plasmodium berghei parasites exhibit growth delay and nuclear DNA damage. Free Radic Biol Med. 95, 43-54. doi: 10.1016/j.freeradbiomed.2016.02.032

Pino, P., Foth, B. J., Kwok, L. Y., Sheiner, L., Schepers, R., Soldati, T., et al. (2007). Dual targeting of antioxidant and metabolic enzymes to the mitochondrion and the apicoplast of Toxoplasma gondii. PLoS Pathog. 3:e115. doi: 10.1371/journal. ppat.0030115

Shalem, O., Sanjana, N. E., Hartenian, E., Shi, X., Scott, D. A., Mikkelson, T., et al. (2014). Genome-scale CRISPR-Cas9 knockout screening in human cells. Science. 343, 84-87. doi: 10.1126/science. 1247005

Shojaee, S., Parhiz, H., Eshaghi, A., Emami, S. A., Asili, J., Behravan, J., et al. (2014). In vitro protective effects of Scutellaria litwinowii root extract against $\mathrm{H} 2 \mathrm{O} 2$ induced DNA damage and cytotoxicity. J Complement Integr Med. 11, 121-127. doi: 10.1515/jcim-2014-0009

Sidik, S. M., Huet, D., Ganesan, S. M., Huynh, M. H., Wang, T., Nasamu, A. S., et al. (2016). A Genome-wide CRISPR Screen in Toxoplasma Identifies Essential Apicomplexan Genes. Cell 166, 1423.e-1435.e. doi: 10.1016/j.cell.2016.08.019

Sidik, S. M., Huet, D., and Lourido, S. (2018). CRISPR-Cas9-based genome-wide screening of Toxoplasma gondii. Nat Protoc. 13, 307-323. doi: 10.1038/nprot. 2017.131

Silva, R. C. D., and Langoni, H. (2009). Toxoplasma gondii: host-parasite interaction and behavior manipulation. Parasitol Res. 105, 893-898. doi: 10. 1007/s00436-009-1526-6

Wang, Y., Sangaré, L. O., Paredes-Santos, T. C., Hassan, M. A., Krishnamurthy, S., Furuta, A. M., et al. (2020). Genome-wide screens identify Toxoplasma gondii determinants of parasite fitness in IFN $\gamma$-activated murine macrophages. Nat Commun. 11, 5258. doi: 10.1038/s41467-020-18991-8

Webster, J. P. (2010). “Toxoplasmosis of Animals and Humans," in Parasit Vectors, ed. J. P. Dubey (Boca Raton, FL: CRC Press), 3, 1-2. doi: 10.1186/1756-3305-3112
West, A. P., Brodsky, I. E., Rahner, C., Woo, D. K., Erdjument-Bromage, H., Tempst, P., et al. (2011). TLR signalling augments macrophage bactericidal activity through mitochondrial ROS. Nature. 472, 476-480. doi: 10.1038/ nature09973

Xu, H., Qu, F., Xu, H., Lai, W., Andrew Wang, Y., Aguilar, Z. P., et al. (2011). Role of reactive oxygen species in the antibacterial mechanism of silver nanoparticles on Escherichia coli O157:H7. Biometals. 25, 45-53. doi: 10.1007/s10534-0119482-x

Xue, J., Jiang, W., Chen, Y., Gong, F., Wang, M., Zeng, P., et al. (2017). Thioredoxin reductase from Toxoplasma gondii: an essential virulence effector with antioxidant function. FASEB J. 31, 4447-4457. doi: 10.1096/fj.20170 0008R

Yamashita, K., Yui, K., Ueda, M., and Yano, A. (1998). Cytotoxic T-lymphocytemediated lysis of Toxoplasma gondii-infected target cells does not lead to death of intracellular parasites. Infect Immun. 66, 4651-4655. doi: 10.1128/IAI.66.10. 4651-4655.1998

Yang, Z., Min, Z., and Yu, B. (2020). Reactive oxygen species and immune regulation. Int Rev Immunol. 39, 292-298. doi: 10.1080/08830185.2020. 1768251

Zhai, B., He, J. J., Elsheikha, H. M., Li, J. X., Zhu, X. Q., and Yang, X. (2020). Transcriptional changes in Toxoplasma gondii in response to treatment with monensin. Parasit Vectors. 13, 84. doi: 10.1186/s13071-0203970-1

Zhu, W., Li, J., Pappoe, F., Shen, J., and Yu, L. (2019). Strategies Developed by Toxoplasma gondii to Survive in the Host. Front Microbiol. 10:899. doi: 10 . 3389/fmicb.2019.00899

Conflict of Interest: The authors declare that the research was conducted in the absence of any commercial or financial relationships that could be construed as a potential conflict of interest.

Copyright (C) 2021 Chen, Liu, Xue, Zhang, Geng, Wang and Jiang. This is an openaccess article distributed under the terms of the Creative Commons Attribution License (CC BY). The use, distribution or reproduction in other forums is permitted, provided the original author(s) and the copyright owner(s) are credited and that the original publication in this journal is cited, in accordance with accepted academic practice. No use, distribution or reproduction is permitted which does not comply with these terms. 